\title{
Treatment-resistant schizophrenia: current insights on the pharmacogenomics of antipsychotics
}

This article was published in the following Dove Press journal:

Pharmacogenomics and Personalized Medicine

7 November 2016

Number of times this article has been viewed

\author{
John Lally'-3 \\ Fiona Gaughran ${ }^{1,3}$ \\ Philip Timms s,5 $^{4}$ \\ Sarah R Curran ${ }^{5-7}$ \\ 'Department of Psychosis Studies, \\ Institute of Psychiatry, Psychology \\ and Neuroscience, King's College \\ London, London, UK; ${ }^{2}$ Department of \\ Psychiatry, Royal College of Surgeons \\ in Ireland, Beaumont Hospital, Dublin, \\ Ireland; ${ }^{3}$ National Psychosis Service, \\ ${ }^{4}$ START Team, South London and \\ Maudsley NHS Foundation Trust, \\ ${ }^{5}$ King's College London, ${ }^{6}$ South West \\ London and St George's Mental \\ Health NHS Foundation Trust, ${ }^{7} \mathrm{St}$ \\ George's University of London, \\ London, UK
}

\begin{abstract}
Up to $30 \%$ of people with schizophrenia do not respond to two (or more) trials of dopaminergic antipsychotics. They are said to have treatment-resistant schizophrenia (TRS). Clozapine is still the only effective treatment for TRS, although it is underused in clinical practice. Initial use is delayed, it can be hard for patients to tolerate, and clinicians can be uncertain as to when to use it. What if, at the start of treatment, we could identify those patients likely to respond to clozapine - and those likely to suffer adverse effects? It is likely that clinicians would feel less inhibited about using it, allowing clozapine to be used earlier and more appropriately. Genetic testing holds out the tantalizing possibility of being able to do just this, and hence the vital importance of pharmacogenomic studies. These can potentially identify genetic markers for both tolerance of and vulnerability to clozapine. We aim to summarize progress so far, possible clinical applications, limitations to the evidence, and problems in applying these findings to the management of TRS. Pharmacogenomic studies of clozapine response and tolerability have produced conflicting results. These are due, at least in part, to significant differences in the patient groups studied. The use of clinical pharmacogenomic testing - to personalize clozapine treatment and identify patients at high risk of treatment failure or of adverse events - has moved closer over the last 20 years. However, to develop such testing that could be used clinically will require larger, multicenter, prospective studies.
\end{abstract}

Keywords: personalized medicine, pharmacogenetics, treatment resistant psychosis, clozapine, pharmacokinetic, pharmacodynamic

\section{Introduction}

Treatment-resistant schizophrenia (TRS) affects $\sim 30 \%$ of people with a diagnosis of schizophrenia. ${ }^{1}$ TRS is defined as nonresponse to at least two trials of antipsychotic medication of adequate dose and duration, ${ }^{2}$ at which point, the antipsychotic clozapine is indicated. Interestingly, clozapine does not work better than other antipsychotics in first-episode cases. ${ }^{3}$ Recent work suggests that different underlying mechanisms are responsible for the symptoms in TRS. ${ }^{4}$ The changes in presynaptic dopamine transmission usually seen in schizophrenia are absent in TRS, ${ }^{5}$ but we do see changes in anterior cingulate glutamate activity. ${ }^{6}$ It is therefore not surprising that other antipsychotics, which all have their main effects on dopamine receptors, fail to work in people with TRS. This may come to be seen less as treatment resistance and more as a failure to direct treatment toward the relevant underlying problem.

Clozapine is unique as it is the only evidence-based treatment for TRS, ${ }^{2,7,8}$ with $60 \%-70 \%$ of those treated showing a response. ${ }^{9}$ However, some patients with TRS do not respond to clozapine. At present, we can identify neither those who will
Correspondence: Sarah R Curran West London and Mental Health NHS Foundation Trust, 6I Glenburnie Road, London SWI7 7DJ, UK Tel +442035234644

Email Sarah.curran@kcl.ac.uk 
improve on clozapine nor those who will not respond to other antipsychotics.

Despite its unique efficacy in TRS, clozapine is underprescribed in most countries. Levels of use are far less than the $\sim 50 \%-60 \%$ of TRS patients who could benefit from it. ${ }^{10-12}$ The evidence suggests that it is only used after a delay of several years. ${ }^{13}$ The reasons for this include a fear of side effects, and the inconvenience of therapeutic blood monitoring. This means that many who could benefit from clozapine do not. ${ }^{14,15}$ Moreover, when clozapine is not used in TRS, patients are often treated with nonevidence-based, high-toxicity, high-dose antipsychotic treatments, and polypharmacy. ${ }^{13}$ If clozapine does work, it can be transformative, improving psychotic symptoms, function, and longevity. However, the process of establishing its efficacy (or otherwise) can be lengthy (up to a year) and grueling for the patient. This evaluation of efficacy and side effects is more difficult because there is really no alternative medication for TRS.

There are currently no evidence-based pharmacotherapies for the $30 \%$ of TRS patients who fail to respond to clozapine $^{9,16}$ or those who discontinue clozapine due to adverse events. ${ }^{17,18}$ As well as facilitating the use of clozapine, pharmacogenomics and personalized medicine could support the development of new medications.

\section{Personalized medicine and pharmacogenomics in TRS}

Personalized, or precision medicine uses "genetic or other biomarker information to improve the safety, effectiveness, and health outcomes of patients via more efficiently targeted risk stratification, prevention, and tailored medication and treatment management approaches", ${ }^{19}$

In TRS, by considering a person's individual genomic, epigenetic, molecular, cellular, clinical, behavioral, and environmental characteristics, it should be possible to tailor appropriate preventative and therapeutic interventions to that individual. This would allow for the safer and timelier introduction of clozapine in patients where it is likely to be effective.

The potential benefits and function of pharmacogenomics in schizophrenia are listed in Table 1.

\section{Terminology \\ Pharmacogenomics}

Pharmacogenomics looks at how genes control drug pharmacokinetics and pharmacodynamics. ${ }^{20}$ The term is often used interchangeably with the term pharmacogenetics. Pharmacogenetics usually refers to how a specific gene or a set of genes can influence a patient's response to medicine(s).
Table I Uses of tools provided by pharmacogenomic biomarkers in TRS

Avoid toxicity and subsequent ADRs

Avoid underdosing and subsequent lack of efficacy

Avoid drug use by hypersensitive individuals

Improve clinical diagnosis

Rescue drugs previously withdrawn because of ADRs

Note: Reproduced with permission of Royal College of Psychiatrists via PLSClear, Lally J, MacCabe JH. Personalised approaches to pharmacotherapy for schizophrenia. ${ }^{117}$

Abbreviations: TRS, treatment-resistant schizophrenia; ADRs, adverse drug reactions.

Pharmacogenomics looks at how a person's whole genetic makeup can influence his/her responses to medicine(s). Early studies focused on pharmacogenetic approaches, looking at groups of genes that seemed to be likely to be involved with a particular disorder - "candidate" genes. Now, with newer technologies, pharmacogenomic approaches are more common.

In this article, we use the term pharmacogenomics to refer to both approaches.

\section{Epigenetics}

Epigenetics refers to the regulation of translation of DNA. This is mainly through changes in DNA methylation and chromatin structure, histone modification, RNA editing, and nontranscriptional gene silencing via micro-RNAs. ${ }^{21,22}$

\section{Pharmacogenomics in TRS}

Patients with TRS have an excess of rare disruptive variants both in gene targets of antipsychotics and in genes with evidence for a role in antipsychotic efficacy. ${ }^{23,24} \mathrm{~A}$ number of studies in TRS patients have looked at the effects of variations in the genes responsible for the effectiveness, adverse effects, and metabolism of clozapine. ${ }^{25-28}$ Newer genomic approaches using genome-wide association study (GWAS) and exome sequencing (to identify rare as well as common genetic variants across the genome) are set to facilitate a new era of pharmacogenomic testing as a guide to personalized treatments. $^{29}$

Barriers to pharmacogenomic testing in TRS are outlined in Table 2, and the characteristics of TRS which attenuate some of these challenges are shown in Table 3.

\section{Pharmacogenomics and clozapine response}

One way to use pharmacogenomic testing in TRS would be to identify specific genetic variations that predict a good response to clozapine, or a low risk of adverse events. Prescribing decisions could then be informed by the genetic test findings. 
Table 2 Challenges in using pharmacogenomics to predict clozapine effect in TRS

Characterizing/quantifying drug response
Measuring antipsychotic efficacy
Nonadherence
Treatment duration - early benefits with antipsychotic response vs
longer duration of effect with clozapine
Concurrent medication use - mood stabilizers; crossover of
antipsychotics during switching
Patient characteristics
Differential diagnosis and unclear diagnostic boundaries
Illness course - first-episode psychosis and TRS
Comorbidities - substance misuse; depression
Risk of neutropenia increased in those of African Caribbean ethnicity
Baseline characteristics: eg, lower BMl and greater risk of weight gain
with clozapine treatment

Abbreviations: TRS, treatment-resistant schizophrenia; BMI, body mass index.

Table 3 Characteristics of TRS which make it a more useful population in which to conduct pharmacogenomic studies

Increased uniformity in diagnosis

Ability to monitor adherence with plasma clozapine concentrations

Long-term follow-up of TRS patients within clinical services

The existence of registers for clozapine-monitoring services

Abbreviation: TRS, treatment-resistant schizophrenia.

Two meta-analyses confirm the importance of the dopaminergic system, ${ }^{28,30}$ and one confirms the impact of the serotonergic system for the antipsychotic effect of clozapine..$^{25}$

\section{Dopaminergic system}

A dopamine receptor type 3 functional polymorphism, Ser$9 G l y$, has been associated with clozapine efficacy in several studies. $^{31,32}$ The direction of this association was further shown in a meta-analysis, although it was not found to be statistically significant. ${ }^{30}$ Genetic variants of the dopamine receptors type 2 and type 1 and dopamine transporter haplotypes have also been found to be associated with clozapine efficacy. ${ }^{26,33}$ Overall, these findings suggest that the dopaminergic system plays some part in mediating clozapine response. However, a recent meta-analysis ${ }^{25}$ did not identify the previously reported association between dopamine genes DRD2 rs 1799732 and DRD3 rs6280 and clozapine response. ${ }^{26,28}$ This study ${ }^{25}$ applied a stricter inclusion criteria than the previous meta-analysis, ${ }^{26}$ only including studies where clozapine was investigated alone (rather than with other antipsychotics).

\section{Serotonergic system}

Several serotonergic receptor type 2A (5-HT2A) gene polymorphisms have been associated with response to clozapine, ${ }^{34}$ although these associations have not been universally replicated. ${ }^{27,35}$ Studies have demonstrated an association between clozapine efficacy and genetic variants in the serotonin receptor type $2 \mathrm{~A}(5-H T 2 A),{ }^{34}$ type $2 \mathrm{C}(5-H T 2 C),{ }^{36}$ and type $6(5-H T 6)^{37}$ and serotonin transporter $(5-H T T)$ genes, ${ }^{36}$ although these findings have not been consistently replicated. ${ }^{26-28}$ The most recent meta-analysis identified three genetic variants within serotonin genes associated with the response to clozapine: rs6313 and rs6314 within the 5-HTR2A gene and rs 1062613 within the $5-H T 3 A$ gene. ${ }^{25}$

No single polymorphism is predictive of clozapine response. So, attempts have been made to combine polymorphisms in several genes to predict such a treatment response. A landmark study was conducted by Arranz et al, in which one test combined six different polymorphisms in neurotransmitter receptor-related genes (the included polymorphisms were 5-HT2A 102-T/C and His452Tyr, 5-HT2C 330-GT/244-CT, and Cys23Ser, 5-HTTLPR, H2 1018-G/A). This resulted in a $77 \%$ success in the prediction of clozapine response $(P=0.0001) .{ }^{36}$ This study was the first demonstration that pharmacogenomics could be used to personalize a psychiatric treatment, and this test was subsequently marketed. However, this finding was not replicated, ${ }^{38}$ and the test was withdrawn from the market. However, there were differences in clinical characteristics in the replication sample from the sample in the original study. The replication sample had a shorter period of clozapine use compared to the original study, which assessed long-term clozapine treatment (mean duration $>1$ year). ${ }^{36}$ The shorter duration of clozapine use in the replication sample may have led to some being prematurely categorized as nonresponders, ${ }^{39}$ as clozapine response can take up to 12 months. ${ }^{9}$

\section{Metabolism of clozapine - CYPIA2 enzyme}

Pharmacokinetic research in schizophrenia has largely focused on the cytochrome P450 (CYP) family. It was hoped that genotyping for CYP enzyme deficiencies could offer a relatively simple solution for optimizing dosing and predicting response to clozapine. However, this has not proved consistent in practice. The genes coding for these enzymes are highly polymorphic, and the effects of many of the genetic differences contribute to differential metabolism of psychotropic agents. Patient phenotypes can be grouped into three categories - poor metabolizers, extensive metabolizers (corresponding to normal CYP activity), and ultrarapid metabolizers. ${ }^{40}$

Therapeutic drug monitoring of plasma clozapine and of its major plasma metabolite $\mathrm{N}$-desmethylclozapine 
(norclozapine) in a predose sample can help to track adherence, and to adjust dose to minimize toxicity. For therapeutic effectiveness, a minimum threshold plasma clozapine level has been identified at $0.35 \mathrm{mg} / \mathrm{L} .^{41-45}$ Monitoring plasma levels of clozapine can identify the following:

- Patients who do not reach therapeutic plasma concentrations at expected therapeutic doses

- Those who have reached an adequate dose (giving plasma clozapine concentrations of $0.35-0.5 \mathrm{mg} / \mathrm{L}$ )

- Those who need prophylactic treatment with antiepileptic drugs to support a trial of a higher plasma clozapine concentration $(>0.6 \mathrm{mg} / \mathrm{L})$

- Partial responders who may benefit from drug augmentation

- Those who have plasma toxicity

The CYP1A2 enzyme is primarily responsible for clozapine metabolism. The genetic studies of clozapine drug response are supported by the identification of multiple functional variants in CYP1A2 ${ }^{44,45}$ with well-defined effects on clozapine metabolism. A number of studies have provided evidence to suggest that the $C Y P 1 A 2 * 1 F$ allele is associated with clozapine response, ${ }^{46-48}$ with the response being linked to plasma concentration levels in the study by Eap et al. Further studies have failed to identify an association between the CYP1A2 polymorphism and plasma clozapine concentrations, when controlling for clozapine dose and body weight. ${ }^{49} \mathrm{CYP} 1 \mathrm{~A} 2 * 1 \mathrm{~F}$ polymorphisms were associated with a super-refractory schizophrenia group of patients, compared to controls, thus replicating previous work, and identifying this polymorphism as a moderator of clozapine response. ${ }^{50}$ However, as is the case in clozapine pharmacodynamic pharmacogenetic research, other studies have not replicated these findings in relation to CYP1A2 polymorphism and clozapine response. ${ }^{51,52}$ Ethnic variation between the study populations has been suggested as a cause of this, with there being a higher frequency of the $C Y P 1 A 2 * 1 F$ allele in those of European ancestry. ${ }^{27}$

Individuals with increased activity of CYP1A2 enzymes are likely to have reduced levels of medication metabolized by that pathway. Case series have reported ultrarapid metabolizers of clozapine presenting as resistant to treatment, and conversely with increased plasma clozapine concentrations occurring with the concurrent use of fluvoxamine, a CYP1A2 inhibitor. ${ }^{53}$ There is substantial individual variability in plasma clozapine concentrations, with higher concentrations in men and lower concentrations in those who smoke. ${ }^{54} \mathrm{~A}$ mutation $(C Y P 1 A 2 * 1 F)$ in intron 1 , which confers a high inducibility of CYP1A2 in smokers, is a suggested explanation for this rapid CYP1A2 activity. ${ }^{55}$ However, pharmacogenetic testing for CYP1A2 variations in relation to clozapine metabolism remains at an early stage. Larger studies are needed in clozapine-treated TRS patients, which clearly identify concurrent inducers (such as smoking), in order to clarify the relationship between faulty CYP1A2 alleles and plasma clozapine concentrations.

The inconsistent findings in relation to CYP1A2 and clozapine response were highlighted in a recent systematic review, which identified only a single-nucleotide polymorphism (SNP) in ABCD1 (3435TT (rs1045642)) to be predictive of plasma clozapine concentrations and response to clozapine, ${ }^{56}$ but further longitudinal studies are required to clarify the role of ABCD1.

Pharmacogenomic testing has been done with warfarindosing algorithms, where both genetic and nongenetic factors are used to tailor warfarin dosing. ${ }^{57}$ However, the translation of pharmacogenomic testing in predicting clozapine response has not, so far, been successful. Much of the research has focused on the CYP system, but at the moment, the use of CYP testing to guide the prescribing and dosing of clozapine cannot be justified.

\section{Clozapine and the glutamate system}

Even though clozapine is our only evidence-based treatment in TRS, we still do not understand how it works. This limits our ability to generate hypotheses as to which pharmacogenomic tests might be relevant. It has been suggested that the glutamate system may mediate response to clozapine, ${ }^{58}$ and this had been investigated more recently. ${ }^{59}$ Both preclinical and human studies have suggested that clozapine augmentation of glutamatergic neurotransmission leads to reductions in central glutamate levels. This has been suggested as a possible mechanism mediating clozapine response. ${ }^{60-62}$

The role of glutamate in the pathogenesis of schizophrenia is supported by recent findings from the Psychiatric Genomics Consortium and other studies. Genome-wide significant associations with schizophrenia have been observed in glutamate system genes GRM3, GRIN2A, GRIA1, and GRIN2B. ${ }^{63,64}$ Neuroimaging studies have provided evidence that there are biological differences in glutamatergic neurotransmission between treatment-resistant and treatmentresponsive schizophrenia. ${ }^{5,6}$ TRS patients have demonstrated higher glutamate levels in the anterior cingulate cortex, ${ }^{6}$ with relatively normal dopamine functioning, in comparison to treatment-responsive patients..$^{5}$ These observations indicate that the persistence of symptoms in TRS may be associated 
with elevated anterior cingulate glutamate levels. In TRS, a handful of studies have investigated glutamate system genes in relation to clozapine response. These have largely focused on variants in GRIN2B, which codes for the $2 \mathrm{~B}$ subunit of the glutamate $N$-methyl-d-aspartate receptor. ${ }^{65}$ Further work is needed to clarify any potential role for the glutamate system in the pathophysiology of TRS and clozapine response. We need to investigate a wider variety of glutamate genetic variants, using prospective study samples, to link the genetic findings to neuroimaging, and phenotypic characteristics, including plasma clozapine concentrations.

\section{Pharmacogenomics and clozapine adverse events Clozapine and agranulocytosis}

One of the main reasons for the underuse of clozapine is patient and clinician fears about sudden clozapine-induced agranulocytosis (CIA). ${ }^{66}$ This occurs with an incidence of $0.8 \%$ at 1 year after starting clozapine treatment. ${ }^{67}$ The highest incidence is at $6-18$ weeks. ${ }^{68}$ The mechanism of this idiosyncratic event is unclear, though it is certainly multifactorial, with some evidence for genetic variance increasing the susceptibility to CIA. ${ }^{69}$

The best genetic evidence is for dysfunction in the human leukocyte antigen (HLA) system, composed of genes that are important in immune system modulation. A recent GWAS and exome-sequencing analysis reported significant associations between genetic variants in HLA and CIA. This included genetic variants involved in the $H L A-D Q B 1$ locus (a single amino acid at HLA-DQB1 (126Q) and an amino acid change in the extracellular binding pocket of $H L A-B(158 T)) .{ }^{69} \mathrm{~A}$ case-control study found that the odds of developing CIA were 16.9 times higher in patients carrying a cytosine instead of the usual guanine $D Q B 1$ genotype. $^{70}$ This SNP was incorporated into a commercially available test, with a sensitivity of $21.5 \%$ and a specificity of $98.4 \%$ for detecting the haplotype, indicating a 5.1\% risk of developing agranulocytosis if the haplotype is present. ${ }^{70}$ Although the $H L A-D Q B 1$ locus may be implicated in CIA development, for the test to be clinically useful, it requires high sensitivity and specificity, and thus, the low sensitivity of the test has limited its use in clinical settings. ${ }^{71}$ This test gives a $1 \%$ $(0.05 \times 0.22)$ chance of identifying patients at risk of developing CIA, which is not very different from the risk for all patients treated with clozapine $(0.8 \%) .^{71,72}$

So far, a dose-dependent link between plasma clozapine concentrations and the risk of neutropenia and agranulocytosis has not been consistently demonstrated. ${ }^{73,74}$ However, a recent GWAS meta-analysis identified a novel genome-wide significant association with clozapine-associated neutropenia and rs149104283, intronic to transcripts of SLCO1B3 and $S L C O 1 B 7$, members of a family of hepatic transporter genes involved in drug uptake. ${ }^{75}$ This study ${ }^{75}$ offers a tantalizing suggestion that CIA may be related to plasma concentrations while offering a novel link between clozapine pharmacokinetics and bioavailability and the genetic risk of neutropenia/ agranulocytosis.

The replication of an association between CIA and genetic variants involved in the $H L A-D Q B 1$ locus ${ }^{69,76-78}$ is promising, but the majority of those who develop a CIA are not carriers of the risk alleles. So, none of these pharmacogenomic tests are yet clinically useful. ${ }^{72}$

\section{Clozapine and metabolic disturbance - candidate gene studies}

Schizophrenia is associated with increased rates of cardiovascular morbidity ${ }^{79-82}$ and associated excess premature death, which translates to a 15- to 20-year shortened life expectancy for those with schizophrenia. ${ }^{83,84}$ There is an increased prevalence of weight gain, dyslipidemia, and type 2 diabetes seen with both clozapine and olanzapine. ${ }^{80,85} \mathrm{Clo-}$ zapine is especially associated with weight gain, which can occur early in the course of treatment, before plateauing as the treatment continues. ${ }^{86-88}$

For clozapine-associated weight gain, the only consistently replicated genetic variant is the $759 \mathrm{~T} / \mathrm{C}$ polymorphism in the promoter region of the HTR2C gene (rs3813929). ${ }^{89-91}$ Those clozapine patients homozygous for the HTR2C gene 759C polymorphism have been shown to have increased obesity rates at 6 months of clozapine treatment. ${ }^{92}$ Conversely, those with the $\mathrm{T}$ allele for this polymorphism have shown less weight gain over the course of the first 6 months of clozapine treatment. ${ }^{93,94}$ However, as is typical of candidate gene studies, these results have not been consistently replicated, with frequent findings of no associations between the $-759 \mathrm{C} / \mathrm{T}$ polymorphism of the HTR $2 C$ gene and clozapine-associated weight gain and obesity. ${ }^{95-97}$ Further, in a recent review, a metaanalysis could not be performed on genes associated with weight gain due to a lack of genetic data from studies in which clozapine was analyzed separately to other antipsychotics. ${ }^{25}$

Other candidate genes identified to be associated with clozapine-induced weight gain include $L G,{ }^{98-100} T N F \alpha,{ }^{101}$ CNR $1,{ }^{102}$ ADR $_{2 A},{ }^{103,104}$ MC4R, ${ }^{105,106}$ and BDNF genes. ${ }^{107}$

Metabolic syndrome associated with clozapine use has been associated with polymorphisms in HTR2C, ${ }^{108-111} \mathrm{LG}$ (G allele of the $-2548 A / G L G$ promoter polymorphism), ${ }^{100}$ the INSIG 2 
(INSIG2 rs 11123469 C allele), which encodes a protein which mediates feedback control of lipid metabolism, with the $\mathrm{C}$ allele significantly overrepresented in those with metabolic syndrome, ${ }^{112}$ and MTHFR genes (MTTP rs1800591 T allele). ${ }^{13,114}$

An increased risk of dyslipidemia secondary to clozapine use is associated with a polymorphism in the PRKAR2B gene, detected in a GWAS of participants from the Clinical Antipsychotic Trials of Intervention Effectiveness (CATIE) study. ${ }^{115}$ ApoC3 (TG haplotype) and ApoA5 (CG haplotype) genes were associated with decreased serum triglyceride and serum cholesterol levels, respectively, in clozapine-treated patients. The ApoC3 CC haplotype was associated with increased serum triglyceride levels. ${ }^{16}$

Table 4 summarizes significant findings from candidate gene studies of clozapine efficacy and side effe cts. $^{32-37,92-94,96,100,106,108,109,117-136}$

\section{Epigenetics}

Studies of genetic associations with schizophrenia are characterized by nonreplication and significant heterogeneity. The heterogeneous course of schizophrenia makes it difficult to apply traditional gene-environment-based approaches ${ }^{137}$ and has led to speculation that epigenetic factors may mediate susceptibility and account for the "missing heritability". ${ }^{138,139}$ Epigenetic influences on disease phenotypes may explain the effect of early life stressors on risk of psychosis in later life.

\section{Epigenetics and antipsychotic use/ development}

The dynamic nature of the epigenome means that, unlike pathogenic DNA sequence mutations, epigenetic disruption is potentially reversible, and thus a realistic target for pharmacological intervention. Methylation of a promoter $\mathrm{CpG}$ island located $\sim 30 \mathrm{~kb}$ upstream of the gene encoding MEK1 was significantly correlated with lifetime antipsychotic use in postmortem frontal cortex brain samples. ${ }^{140}$ Epigenetic changes on GABAergic and glutamatergic gene promoters have been suggested as explanations for the therapeutic action of clozapine. ${ }^{141-143}$ This occurs at least in part due to increased GABAergic activity mediated by histone methylation and

Table 4 Positive and negative candidate gene studies of clozapine treatment response and clozapine-induced metabolic disturbance in schizophrenia

\begin{tabular}{|c|c|c|c|}
\hline Gene & Variant & Reported association & $\begin{array}{l}\text { Nonsignificant associations } \\
\text { (references) }\end{array}$ \\
\hline \multicolumn{4}{|l|}{ Dopamine } \\
\hline DAT & Multiple ${ }^{33}$ & Improved psychotic symptoms & $|2|$ \\
\hline$D I$ & Multiple ${ }^{1 / 8,119}$ & Improved psychotic symptoms & - \\
\hline D2 & $\mathrm{Taq} A / B^{120}$ & Improved psychotic symptoms & 35,122 \\
\hline D3 & Ser9Gly ${ }^{32}$ & $\begin{array}{l}\text { Increased efficacy in those with } \\
\text { Ser allele }\end{array}$ & 36,123 \\
\hline \multicolumn{4}{|l|}{ Serotonin } \\
\hline \multirow[t]{3}{*}{$5-H T 2 A$} & $102 \mathrm{~T} / \mathrm{C}^{34}$ & $\begin{array}{l}\mathrm{C} / \mathrm{C} \text { genotype: with improved } \\
\text { response }\end{array}$ & 124,127 \\
\hline & $-1438 \mathrm{G} / \mathrm{A}^{35}$ & G/G genotype poorer response & $\begin{array}{l}\text { I } 28 \text { (group treated with } \\
\text { clozapine, amisulpride, } \\
\text { olanzapine, or risperidone) }\end{array}$ \\
\hline & His 452Tyr ${ }^{124,125}$ & Tyr associated with nonresponse & 127,129 \\
\hline 5-HT2C & Cys23Ser ${ }^{126}$ & $\begin{array}{l}\text { Ser associated with increased } \\
\text { efficacy }\end{array}$ & 124,130 \\
\hline 5-HT6 & $267 \mathrm{~T} / \mathrm{C}^{37}$ & $\begin{array}{l}\text { Improved response in } \mathrm{T} / \mathrm{T} \\
\text { genotype }\end{array}$ & $|3|$ \\
\hline 5-HT2C & $759 \mathrm{C} / \mathrm{T}^{92-94}$ & $\begin{array}{l}C \text { allele associated with weight gain } \\
\text { and } T \text { allele with a protective effect }\end{array}$ & 96 \\
\hline 5-HT2C & $\begin{array}{l}\text { Cys23Ser-polymorphisms rs5 I8I47, rs I 4|4334, } \\
\text { and 5-HTR }{ }_{2 C}: \text { c. I-I42948(GT)n 108,109 }\end{array}$ & $\begin{array}{l}\text { Increased risk of metabolic } \\
\text { syndrome }\end{array}$ & \\
\hline LEP & $-2548 \mathrm{~A} / \mathrm{G}$ (GG/GA genotype) ${ }^{100}$ & $\begin{array}{l}\text { Increased weight gain and risk of } \\
\text { metabolic syndrome }\end{array}$ & 132 \\
\hline$M C 4 R$ & $\begin{array}{l}\text { rs I77823 I } 3 \text { C allele (CC genotype) } \\
\text { rs8087522 A allele }\end{array}$ & Increased weight gain & 134 \\
\hline D2 & rs4436578 C allele ${ }^{135}$ & Increased weight gain & \\
\hline$T N F a$ & $\begin{array}{l}308 \mathrm{G}>\mathrm{A} \text { polymorphism } T N F a \text { gene }(-308 \mathrm{GG} \\
\text { genotype })^{101}\end{array}$ & Increased weight gain & 136 \\
\hline
\end{tabular}

Notes: Although numerous studies suggest that clozapine-induced side effects and efficacy are associated with candidate gene polymorphisms, most findings are of modest effect, with inconsistent results to date (ie, multiple negative studies of candidate genes exist). Reproduced with permission of Royal College of Psychiatrists via PLSClear, Lally J, MacCabe JH. Personalised approaches to pharmacotherapy for schizophrenia. ${ }^{117}$ 
chromatin relaxation, and the targeting of DNA demethylation via GADD45b. ${ }^{142}$ Clozapine, but not haloperidol, is associated with the induction of nuclear $\mathrm{H} 3 \mathrm{~K} 9$ acetylation ${ }^{144}$ and an increase of GADD45b mRNA in mice. ${ }^{142}$ Epigenetic research into therapeutic mechanisms of clozapine action remains in its infancy, though findings to date suggest the possibility of future tests to predict clozapine responders and of novel therapeutic interventions.

\section{Challenges in applying pharmacogenomics in TRS and future directions}

Several factors contribute to the difficulty in implementing pharmacogenomic testing to predict clozapine tolerability and efficacy. Schizophrenia is a heterogeneous disorder, characterized by variability in clinical presentation, which makes it a challenging phenotype to accurately assess. While TRS may represent a distinct and more uniform subtype of schizophrenia, ${ }^{145}$ it is likely that remaining heterogeneity continues to obscure true genetic signals. Varying environmental and clinical factors impacting on clozapine response and tolerability further complicate pharmacogenomic research.

Some potential clinical risk factors for TRS have been suggested, such as a young age of illness onset (and specifically onset before the age of $20^{146}$ ), an insidious onset, a greater severity of negative symptoms at illness onset, living in less urban environments, comorbid personality disorders, and cumulative effects of lifetime trauma and adversity. ${ }^{146-153}$ However, to date, the predictive value of demographic and clinical risk factors for TRS, linked to pharmacogenomic findings, has not been widely investigated. One recent study identified an association between treatment resistance and polygenic risk score, an association which was stronger in those with a younger age of illness onset and with poorer premorbid functioning. ${ }^{149} \mathrm{~A}$ more recent study, comparable in size, failed to identify an association between treatment resistance and polygenic risk score. ${ }^{153}$ Given these equivocal findings, the use of common genetic variants to index a polygenic risk score to predict treatment resistance requires further evaluation using larger case-control population samples, and factoring in other clinical and demographic risk factors. This approach could clarify the utility of the polygenic risk score in predicting TRS.

Previous attempts to identify clinical predictors of clozapine response have generally identified few predictors. The most consistently identified predictors of clozapine response include a later age of illness onset, ${ }^{154-156}$ more severe positive symptoms, ${ }^{154,157,158}$ an earlier use of clozapine in the illness course when treatment resistance emerges, ${ }^{159}$ and related to this, a lower number of antipsychotic trials and hospitalizations prior to clozapine use. ${ }^{160}$ As demonstrated in this review, candidate gene and genome sequence studies alone have not proved successful in identifying consistent predictors of clozapine response. Future pharmacogenomic studies could benefit from incorporating clinical risk factors for clozapine response, to guide the development of valid and useful clozapine treatment algorithms for predicting response.

Pharmacogenomic studies of clozapine have also been limited by sample size. This is further compounded by the heterogeneity of participants, few measures of clozapine adherence, levels of concurrent medications, lack of controlling for confounding factors such as smoking, and the absence of an agreed response to clozapine by a numerical reduction in scale scores (such as the Positive and Negative Syndrome Scale or the Brief Psychiatric Rating Scale score).

Probably as a result of such limitations, most positive candidate gene studies have not provided sufficiently robust findings nor been replicated. Meta-analysis has confirmed the need for replication studies of much larger sample sizes to detect real associations. ${ }^{25,27}$ Most pharmacogenomic studies in clozapine use have focused on candidate genes coding for specific enzymes believed to be involved in the absorption, distribution, metabolism, and/or excretion of antipsychotic medications. ${ }^{27,28,89}$ Studies using the candidate gene approach are inherently limited by the genes chosen, while linkage method studies require families and are impractical for most pharmacogenomic questions. The introduction of GWAS has opened the doors to genetic research which transcends candidate gene studies. ${ }^{63,69,149,161}$ GWAS research has developed rapidly, and there is a growing set of GWASs related to phenotypes, including TRS. ${ }^{145}$ However, this remains a novel area, and there are but a handful of studies assessing clozapine response using a polygenic risk-scoring method (based on GWAS)..$^{24,161,162}$ GWAS has been more widely applied in the identification of genetic variants associated with clozapine adverse events, such as agranulocytosis ${ }^{69}$ and metabolic disturbance. In the most noteworthy GWAS of clozapine metabolic effects from the CATIE study, positive associations for metabolic disturbance (SNP in PRKAR2B gene) ${ }^{115}$ were identified, while in other GWASs, associations with the $M C 4 R$ gene and weight gain with clozapine use were seen. ${ }^{106,163}$ However, the concurrent use of multiple antipsychotics and the failure to consider clozapine separately preclude meta-analysis of the genetic variants contributing to clozapine metabolic disturbances. ${ }^{27}$ 


\section{Future directions}

\section{Barriers to implementation of pharmacogenomic} testing in TRS

The translation of pharmacogenomic research findings into clinical practice has been slow in all medical settings. ${ }^{164,165}$ In psychiatry, the limitations of the available tests have prevented the use of pharmacogenomic testing in the clinical use of clozapine and other antipsychotics. The reasons for this include the limitations of the candidate gene approach and study heterogeneity.

Substantial economic barriers also remain. ${ }^{166}$ The stratification of patients with psychotic illness into more refined subsets may advance medication development, but it may also reduce the size of the potential market and deter industry investment. ${ }^{167}$ Drugs developed in this way may take longer to recoup development expenses. It may also prove less economic to develop drugs to treat rarer genetic subtypes of TRS or genetically determined TRS subtypes which are more prevalent in lower income countries. ${ }^{118}$

On the other hand, as technology advances, genotyping should become cheaper. In the future, the focus will shift from genotyping costs to the interpretation and production of reports for clinical use. The clear communication of pharmacogenomic test results will be a critical part of their effective clinical use.

Pharmacogenomic test results for the individual patient should be available for that patient's lifetime. However, due to the fragmentation of health care services, this genetic test information may be lost as the patient moves from one health care setting to another. This could be overcome by using integrated patient records. Currently, in the UK, pharmacogenomic information might sit best in primary care records, ensuring that it is available for all potential prescribers.

Furthermore, clinicians are not used to using this kind of information to inform their prescribing. This is, perhaps, not surprising when these tests have limited clinical usefulness. ${ }^{168}$ For example, in schizophrenia in general, the characterization of CYP genes has not led to the widespread utilization of these tests to predict response and side effects to treatment. ${ }^{169}$ Surveys have indicated that when clinicians have used pharmacogenomic tests, they have focused on the assessment of medication intolerance rather than response. ${ }^{170}$

\section{Overcoming barriers}

Even when pharmacogenomic tests become more clinically informative, it will still be necessary to ensure that clinicians are fully informed of the ways in which such tests can improve clinical practice. Health service providers will need to be convinced that this technology is cost effective and that it represents an improvement over the current trial-and-error approaches to prescribing. Thorough implementation will require clinician education, the incorporation of pharmacogenomic testing advice into clinical guidelines for TRS, and integrated medical records. ${ }^{171}$

\section{Conclusion}

Personalized medicine in the diagnosis and treatment of TRS will involve multiple strands including genetics, neuroimaging, and biomarkers. The use of genomic markers should enable us to create more identifiable homogenous subgroups of schizophrenia patients. In turn, this should mean that we can better identify both those who will respond to clozapine and those who will better tolerate it. Such predictive testing should allow low-risk patients to get the most benefit from clozapine while reducing the risk of adverse events for higher risk patients.

However, given the weakness of the tests currently available, pharmacogenomic testing is not yet at a point where it can effectively inform the clinical use of clozapine. What needs to be done? We need clearly agreed definitions of TRS and standardized measurements of response to treatment. This would allow the construction of large and well-characterized samples which could be subject to prospective assessments. Such studies will need to link genetic data with phenotypic stratification. They will also need to allow for the effects of other factors such as current and historical use of medication, doses and plasma concentrations of clozapine, and lifestyle factors such as smoking.

\section{Disclosure}

FG has received honoraria for advisory work and lectures from Roche, BMS, Lundbeck, Otsaka, and Sunovion, is a collaborator on an NHS Innovations project cofunded by Janssen, and has a family member with professional links to Lilly and GSK, including stock. The other authors, JL, PT, and SC, have no conflict of interest to declare in this work.

\section{References}

1. Meltzer HY. Treatment-resistant schizophrenia-the role of clozapine. Curr Med Res Opin. 1997;14(1):1-20.

2. NICE. Psychosis and Schizophrenia in Adults: Treatment and Management (Clinical Guideline 178). London: Royal College of Psychiatrists; 2014.

3. Lieberman JA, Phillips M, Gu H, et al. Atypical and conventional antipsychotic drugs in treatment-naive first-episode schizophrenia: a 52-week randomized trial of clozapine vs chlorpromazine. Neuropsychopharmacology. 2003;28(5):995-1003.

4. Girgis RR, Phillips MR, Li X, et al. Clozapine v. chlorpromazine in treatment-naive, first-episode schizophrenia: 9-year outcomes of a randomised clinical trial. Br J Psychiatry. 2011;199(4):281-288.

5. Demjaha A, Murray RM, McGuire PK, Kapur S, Howes OD. Dopamine synthesis capacity in patients with treatment-resistant schizophrenia. Am J Psychiatry. 2012;169(11):1203-1210.

6. Demjaha A, Egerton A, Murray RM, et al. Antipsychotic treatment resistance in schizophrenia associated with elevated glutamate levels but normal dopamine function. Biol Psychiatry. 2014;75(5):e11-e13. 
7. Chakos M, Lieberman J, Hoffman E, Bradford D, Sheitman B. Effectiveness of second-generation antipsychotics in patients with treatment-resistant schizophrenia: a review and meta-analysis of randomized trials. Am J Psychiatry. 2001;158(4):518-526.

8. Wahlbeck K, Cheine M, Essali A, Adams C. Evidence of clozapine's effectiveness in schizophrenia: a systematic review and meta-analysis of randomized trials. Am J Psychiatry. 1999;156(7):990-999.

9. Meltzer HY. Treatment of the neuroleptic-nonresponsive schizophrenic patient. Schizophr Bull. 1992;18(3):515-542.

10. Downs JM, Zinkler M. Clozapine: national review of postcode prescribing. Psychiatrist. 2007;31(10):384-387.

11. Nielsen J, Roge R, Schjerning O, Sorensen HJ, Taylor D. Geographical and temporal variations in clozapine prescription for schizophrenia. Eur Neuropsychopharmacol. 2012;22(11):818-824.

12. Stroup TS, Gerhard T, Crystal S, Huang C, Olfson M. Geographic and clinical variation in clozapine use in the United States. Psychiatr Serv. 2014;65(2):186-192.

13. Howes OD, Vergunst F, Gee S, McGuire P, Kapur S, Taylor D. Adherence to treatment guidelines in clinical practice: study of antipsychotic treatment prior to clozapine initiation. Br J Psychiatry. 2012;201(6):481-485.

14. Hayes RD, Downs J, Chang CK, et al. The effect of clozapine on premature mortality: an assessment of clinical monitoring and other potential confounders. Schizophr Bull. 2015;41(3):644-655.

15. Tiihonen J, Lonnqvist J, Wahlbeck K, et al. 11-Year follow-up of mortality in patients with schizophrenia: a population-based cohort study (FIN11 study). Lancet. 2009;374(9690):620-627.

16. Lally J, Tully J, Robertson D, Stubbs B, Gaughran F, MacCabe JH. Augmentation of clozapine with electroconvulsive therapy in treatment resistant schizophrenia: a systematic review and meta-analysis. Schizophr Res. 2016;171(1-3):215-224.

17. Mustafa FA, Burke JG, Abukmeil SS, Scanlon JJ, Cox M. "Schizophrenia past Clozapine": reasons for clozapine discontinuation, mortality, and alternative antipsychotic prescribing. Pharmacopsychiatry. 2015;48(1):11-14.

18. Davis MC, Fuller MA, Strauss ME, Konicki PE, Jaskiw GE. Discontinuation of clozapine: a 15-year naturalistic retrospective study of 320 patients. Acta Psychiatr Scand. 2014;130(1):30-39.

19. Faulkner E, Annemans L, Garrison L, et al. Challenges in the development and reimbursement of personalized medicine-payer and manufacturer perspectives and implications for health economics and outcomes research: a report of the ISPOR personalized medicine special interest group. Value Health. 2012;15(8):1162-1171.

20. Relling MV, Evans WE. Pharmacogenomics in the clinic. Nature. 2015;526(7573):343-350.

21. Feinberg AP, Fallin MD. Epigenetics at the crossroads of genes and the environment. JAMA. 2015;314(11):1129-1130.

22. Bird A. Perceptions of epigenetics. Nature. 2007;447(7143):396-398.

23. Rees E, O'Donovan MC, Owen MJ. Genetics of schizophrenia. Curr Opin Behav Sci. 2015;2:8-14.

24. Ruderfer DM, Charney AW, Readhead B, et al. Polygenic overlap between schizophrenia risk and antipsychotic response: a genomic medicine approach. Lancet Psychiatry. 2016;3(4):350-357.

25. Gressier F, Porcelli S, Calati R, Serretti A. Pharmacogenetics of clozapine response and induced weight gain: a comprehensive review and meta-analysis. Eur Neuropsychopharmacol. 2016;26(2):163-185.

26. Kohlrausch FB. Pharmacogenetics in schizophrenia: a review of clozapine studies. Rev Bras Psiquiatr. 2013;35(3):305-317.

27. Sriretnakumar V, Huang E, Muller DJ. Pharmacogenetics of clozapine treatment response and side-effects in schizophrenia: an update. Expert Opin Drug Metab Toxicol. 2015;11(11):1709-1731.

28. Zhang JP, Malhotra AK. Pharmacogenetics and antipsychotics: therapeutic efficacy and side effects prediction. Expert Opin Drug Metab Toxicol. 2011;7(1):9-37.

29. Iyegbe C, Campbell D, Butler A, Ajnakina O, Sham P. The emerging molecular architecture of schizophrenia, polygenic risk scores and the clinical implications for GxE research. Soc Psychiatry Psychiatr Epidemiol. 2014;49(2):169-182.
30. Hwang R, Zai C, Tiwari A, et al. Effect of dopamine D3 receptor gene polymorphisms and clozapine treatment response: exploratory analysis of nine polymorphisms and meta-analysis of the Ser9Gly variant. Pharmacogenomics J. 2010;10(3):200-218.

31. Scharfetter J, Chaudhry HR, Hornik K, et al. Dopamine D3 receptor gene polymorphism and response to clozapine in schizophrenic Pakistani patients. Eur Neuropsychopharmacol. 1999;10(1): 17-20.

32. Shaikh S, Collier DA, Sham PC, et al. Allelic association between a Ser-9-Gly polymorphism in the dopamine D3 receptor gene and schizophrenia. Hum Genet. 1996;97(6):714-719.

33. Xu M, Xing Q, Li S, et al. Pharacogenetic effects of dopamine transporter gene polymorphisms on response to chlorpromazine and clozapine and on extrapyramidal syndrome in schizophrenia. Prog Neuropsychopharmacol Biol Psychiatry. 2010;34(6): 1026-1032.

34. Arranz M, Collier D, Sodhi M, et al. Association between clozapine response and allelic variation in 5-HT2A receptor gene. Lancet. 1995;346(8970):281-282.

35. Arranz MJ, Munro J, Owen MJ, et al. Evidence for association between polymorphisms in the promoter and coding regions of the 5-HT2A receptor gene and response to clozapine. Mol Psychiatry. 1998;3(1):61-66.

36. Arranz MJ, Munro J, Birkett J, et al. Pharmacogenetic prediction of clozapine response. Lancet. 2000;355(9215):1615-1616.

37. Yu YW, Tsai SJ, Lin CH, Hsu CP, Yang KH, Hong CJ. Serotonin-6 receptor variant $(\mathrm{C} 267 \mathrm{~T})$ and clinical response to clozapine. Neuroreport. 1999;10(6):1231-1233.

38. Schumacher J, Schulze TG, Wienker TF, Rietschel M, Nothen MM. Pharmacogenetics of the clozapine response. Lancet. 2000;356(9228): 506-507.

39. Arranz MJ, Munro J, Osborne S, Collier D, Kerwin RW. Difficulties in replication of results. Lancet. 2000;356(9238):1359-1360.

40. Arranz MJ, de Leon J. Pharmacogenetics and pharmacogenomics of schizophrenia: a review of last decade of research. Mol Psychiatry. 2007;12(8):707-747.

41. Bell R, McLaren A, Galanos J, Copolov D. The clinical use of plasma clozapine levels. Aust N Z J Psychiatry. 1998;32(4):567-574.

42. Kronig MH, Munne RA, Szymanski S, et al. Plasma clozapine levels and clinical response for treatment-refractory schizophrenic patients. Am J Psychiatry. 1995;152(2):179-182.

43. Cooper TB. Clozapine plasma level monitoring: current status. Psychiatr Q. 1996;67(4):297-311.

44. Miller DD, Fleming F, Holman TL, Perry PJ. Plasma clozapine concentrations as a predictor of clinical response: a follow-up study. $J$ Clin Psychiatry. 1994;55 Suppl B:117-121.

45. Spina E, Avenoso A, Facciola G, et al. Relationship between plasma concentrations of clozapine and norclozapine and therapeutic response in patients with schizophrenia resistant to conventional neuroleptics. Psychopharmacology (Berl). 2000;148(1):83-89.

46. Eap CB, Bender S, Jaquenoud Sirot E, et al. Nonresponse to clozapine and ultrarapid CYP1A2 activity: clinical data and analysis of CYP1A2 gene. J Clin Psychopharmacol. 2004;24(2):214-219.

47. Ozdemir V, Kalow W, Okey AB, et al. Treatment-resistance to clozapine in association with ultrarapid CYP1A2 activity and the C-->A polymorphism in intron 1 of the CYP1A2 gene: effect of grapefruit juice and low-dose fluvoxamine. J Clin Psychopharmacol. 2001;21(6):603-607.

48. Balibey H, Basoglu C, Lundgren S, et al. [CYP1A2*1F polymorphism decreases clinical response to clozapine in patients with schizophrenia]. Klin Psikofarmakol B. 2011;21(2):93-99. Turkish.

49. Kootstra-Ros JE, Smallegoor W, van der Weide J. The cytochrome P450 CYP1A2 genetic polymorphisms *1F and *1D do not affect clozapine clearance in a group of schizophrenic patients. Ann Clin Biochem. 2005;42(Pt 3):216-219.

50. de Brito RB, de Carvalho Araújo L, Diniz MJ, et al. The CYP1A2 $-163 \mathrm{C}>\mathrm{A}$ polymorphism is associated with super-refractory schizophrenia. Schizophr Res. 2015;169(1-3):502-503. 
51. Lee ST, Ryu S, Kim SR, et al. Association study of 27 annotated genes for clozapine pharmacogenetics: validation of preexisting studies and identification of a new candidate gene, ABCB1, for treatment response. J Clin Psychopharmacol. 2012;32(4):441-448.

52. Rajkumar AP, Poonkuzhali B, Kuruvilla A, Srivastava A, Jacob M, Jacob KS. Association between CYP1A2 gene single nucleotide polymorphisms and clinical responses to clozapine in patients with treatment-resistant schizophrenia. Acta Neuropsychiatr. 2013;25(1):2-11.

53. Lu ML, Lane HY, Chen KP, Jann MW, Su MH, Chang WH. Fluvoxamine reduces the clozapine dosage needed in refractory schizophrenic patients. J Clin Psychiatry. 2000;61(8):594-599.

54. Rostami-Hodjegan A, Amin AM, Spencer EP, Lennard MS, Tucker GT, Flanagan RJ. Influence of dose, cigarette smoking, age, sex, and metabolic activity on plasma clozapine concentrations: a predictive model and nomograms to aid clozapine dose adjustment and to assess compliance in individual patients. J Clin Psychopharmacol. 2004;24(1):70-78.

55. Dobrinas M, Cornuz J, Oneda B, Kohler Serra M, Puhl M, Eap CB. Impact of smoking, smoking cessation, and genetic polymorphisms on CYP1A2 activity and inducibility. Clin Pharmacol Ther. 2011;90(1):117-125.

56. Krivoy A, Gaughran F, Weizman A, Breen G, MacCabe JH. Gene polymorphisms potentially related to the pharmacokinetics of clozapine: a systematic review. Int Clin Psychopharmacol. 2016;31(4): 179-184.

57. Mega JL, Walker JR, Ruff CT, et al. Genetics and the clinical response to warfarin and edoxaban: findings from the randomised, double-blind ENGAGE AF-TIMI 48 trial. Lancet. 2015;385(9984): 2280-2287.

58. Heresco-Levy U. Glutamatergic neurotransmission modulation and the mechanisms of antipsychotic atypicality. Prog Neuropsychopharmacol Biol Psychiatry. 2003;27(7):1113-1123.

59. Howes O, McCutcheon R, Stone J. Glutamate and dopamine in schizophrenia: an update for the 21st century. J Psychopharmacol. 2015;29(2):97-115.

60. Evins AE, Amico ET, Shih V, Goff DC. Clozapine treatment increases serum glutamate and aspartate compared to conventional neuroleptics. J Neural Transm (Vienna). 1997;104(6-7):761-766.

61. Meshul CK, Bunker GL, Mason JN, Allen C, Janowsky A. Effects of subchronic clozapine and haloperidol on striatal glutamatergic synapses. J Neurochem. 1996;67(5):1965-1973.

62. Pilowsky LS, Bressan RA, Stone JM, et al. First in vivo evidence of an NMDA receptor deficit in medication-free schizophrenic patients. Mol Psychiatry. 2006;11(2):118-119.

63. Schizophrenia Working Group of the Psychiatric Genomics Consortium. Biological insights from 108 schizophrenia-associated genetic loci. Nature. 2014;511(7510):421-427.

64. Kirov G, Pocklington AJ, Holmans P, et al. De novo CNV analysis implicates specific abnormalities of postsynaptic signalling complexes in the pathogenesis of schizophrenia. Mol Psychiatry. 2012;17(2):142-153.

65. Taylor DL, Tiwari AK, Lieberman JA, et al. Genetic association analysis of N-methyl-d-aspartate receptor subunit gene GRIN2B and clinical response to clozapine. Hum Psychopharmacol. 2016;31(2):121-134.

66. Nielsen J, Dahm M, Lublin H, Taylor D. Psychiatrists' attitude towards and knowledge of clozapine treatment. J Psychopharmacol. 2010;24(7):965-971.

67. Alvir JM, Lieberman JA, Safferman AZ, Schwimmer JL, Schaaf JA. Clozapine-induced agranulocytosis. Incidence and risk factors in the United States. N Engl J Med. 1993;329(3):162-167.

68. Atkin K, Kendall F, Gould D, Freeman H, Liberman J, O’Sullivan D. Neutropenia and agranulocytosis in patients receiving clozapine in the UK and Ireland. Br J Psychiatry. 1996;169(4):483-488.

69. Goldstein JI, Jarskog LF, Hilliard C, et al. Clozapine-induced agranulocytosis is associated with rare HLA-DQB1 and HLA-B alleles. Nat Commun. 2014;5:4757.

70. Athanasiou MC, Dettling M, Cascorbi I, et al. Candidate gene analysis identifies a polymorphism in HLA-DQB1 associated with clozapineinduced agranulocytosis. J Clin Psychiatry. 2011;72(4):458-463.
71. Chowdhury NI, Remington G, Kennedy JL. Genetics of antipsychoticinduced side effects and agranulocytosis. Curr Psychiatry Rep. 2011;13(2):156-165.

72. Verbelen M, Collier DA, Cohen D, MacCabe JH, Lewis CM. Establishing the characteristics of an effective pharmacogenetic test for clozapine-induced agranulocytosis. Pharmacogenomics $J$. 2015;15(5):461-466.

73. Centorrino F, Baldessarini RJ, Flood JG, Kando JC, Frankenburg FR. Relation of leukocyte counts during clozapine treatment to serum concentrations of clozapine and metabolites. Am J Psychiatry. 1995;152(4):610-612.

74. Hasegawa M, Cola PA, Meltzer HY. Plasma clozapine and desmethylclozapine levels in clozapine-induced agranulocytosis. Neuropsychopharmacology. 1994;11(1):45-47.

75. Legge, SE, Hamshere, ML, Ripke, S, et al. Clozapine-Induced Agranulocytosis, Genome-wide common and rare variant analysis provides novel insights into clozapine-associated neutropenia. Mol Psychiatry. 2016. Aug 9. doi: 10.1038/mp.2016.137.

76. Saito T, Ikeda M, Mushiroda T, et al. Pharmacogenomic study of clozapine-induced agranulocytosis/granulocytopenia in a Japanese population. Biol Psychiatry. Epub 2016 Feb 11.

77. Yunis JJ, Corzo D, Salazar M, Lieberman JA, Howard A, Yunis EJ. HLA associations in clozapine-induced agranulocytosis. Blood. 1995;86(3):1177-1183.

78. Dettling M, Schaub RT, Mueller-Oerlinghausen B, Roots I, Cascorbi I. Further evidence of human leukocyte antigen-encoded susceptibility to clozapine-induced agranulocytosis independent of ancestry. Pharmacogenetics. 2001;11(2):135-141.

79. Vancampfort D, Stubbs B, Mitchell AJ, et al. Risk of metabolic syndrome and its components in people with schizophrenia and related psychotic disorders, bipolar disorder and major depressive disorder: a systematic review and meta-analysis. World Psychiatry. 2015;14(3):339-347.

80. Vancampfort D, Correll CU, Galling B, et al. Diabetes mellitus in people with schizophrenia, bipolar disorder and major depressive disorder: a systematic review and large scale meta-analysis. World Psychiatry. 2016;15(2):166-174.

81. Gardner-Sood P, Lally J, Smith S, et al. Cardiovascular risk factors and metabolic syndrome in people with established psychotic illnesses: baseline data from the IMPaCT randomized controlled trial. Psychol Med. 2015;45(12):2619-2629.

82. Mitchell AJ, Vancampfort D, Sweers K, van Winkel R, Yu W, De Hert M. Prevalence of metabolic syndrome and metabolic abnormalities in schizophrenia and related disorders--a systematic review and metaanalysis. Schizophr Bull. 2013;39(2):306-318.

83. Saha S, Chant D, McGrath J. A systematic review of mortality in schizophrenia: is the differential mortality gap worsening over time? Arch Gen Psychiatry. 2007;64(10):1123-1131.

84. Chang CK, Hayes RD, Perera G, et al. Life expectancy at birth for people with serious mental illness and other major disorders from a secondary mental health care case register in London. PLoS One. 2011;6(5):e19590.

85. Henderson DC, Cagliero E, Gray C, et al. Clozapine, diabetes mellitus, weight gain, and lipid abnormalities: a five-year naturalistic study. Am J Psychiatry. 2000;157(6):975-981.

86. Bak M, Fransen A, Janssen J, van Os J, Drukker M. Almost all antipsychotics result in weight gain: a meta-analysis. PLoS One. 2014;9(4):e94112.

87. Lamberti JS, Bellnier T, Schwarzkopf SB. Weight gain among schizophrenic patients treated with clozapine. Am J Psychiatry. 1992;149(5):689-690.

88. Allison DB, Mentore JL, Heo M, et al. Antipsychotic-induced weight gain: a comprehensive research synthesis. Am J Psychiatry. 1999; 156(11):1686-1696.

89. Arranz MJ, Rivera M, Munro JC. Pharmacogenetics of response to antipsychotics in patients with schizophrenia. CNS Drugs. 2011; 25(11):933-969.

90. Raja M, Raja S. Clozapine safety, 40 years later. Curr Drug Saf. 2014;9(3):163-195. 
91. Wallace TJ, Zai CC, Brandl EJ, Muller DJ. Role of 5-HT(2C) receptor gene variants in antipsychotic-induced weight gain. Pharmacogenomics Pers Med. 2011;4:83-93.

92. Gunes A, Melkersson KI, Scordo MG, Dahl ML. Association between HTR2C and HTR2A polymorphisms and metabolic abnormalities in patients treated with olanzapine or clozapine. J Clin Psychopharmacol. 2009;29(1):65-68.

93. Miller DD, Ellingrod VL, Holman TL, Buckley PF, Arndt S. Clozapine-induced weight gain associated with the 5HT2C receptor -759C/T polymorphism. Am J Med Genet B Neuropsychiatr Genet. 2005;133B(1):97-100.

94. Reynolds GP, Zhang Z, Zhang X. Polymorphism of the promoter region of the serotonin 5-HT2C receptor gene and clozapine-induced weight gain. Am J Psychiatry. 2003;160(4):677-679.

95. De Luca V, Muller DJ, Hwang R, et al. HTR2C haplotypes and antipsychotics-induced weight gain: $\mathrm{X}$-linked multimarker analysis. Hum Psychopharmacol. 2007;22(7):463-467.

96. Tsai SJ, Hong CJ, Yu YW, Lin CH. $-759 \mathrm{C} / \mathrm{T}$ genetic variation of $5 \mathrm{HT}(2 \mathrm{C})$ receptor and clozapine-induced weight gain. Lancet. 2002;360(9347):1790.

97. Theisen FM, Hinney A, Bromel T, et al. Lack of association between the $-759 \mathrm{C} / \mathrm{T}$ polymorphism of the $5-\mathrm{HT} 2 \mathrm{C}$ receptor gene and clozapine-induced weight gain among German schizophrenic individuals. Psychiatr Genet. 2004;14(3):139-142.

98. Brandl EJ, Frydrychowicz C, Tiwari AK, et al. Association study of polymorphisms in leptin and leptin receptor genes with antipsychoticinduced body weight gain. Prog Neuropsychopharmacol Biol Psychiatry. 2012;38(2):134-141.

99. Kang SH, Lee JI, Han HR, Soh M, Hong JP. Polymorphisms of the leptin and HTR2C genes and clozapine-induced weight change and baseline BMI in patients with chronic schizophrenia. Psychiatr Genet 2014;24(6):249-256.

100. Yevtushenko OO, Cooper SJ, O'Neill R, Doherty JK, Woodside JV, Reynolds GP. Influence of 5-HT2C receptor and leptin gene polymorphisms, smoking and drug treatment on metabolic disturbances in patients with schizophrenia. Br J Psychiatry. 2008;192(6):424-428.

101. Wang YC, Bai YM, Chen JY, Lin CC, Lai IC, Liou YJ. Genetic association between TNF- $\alpha-308 \mathrm{G}>\mathrm{A}$ polymorphism and longitudinal weight change during clozapine treatment. Hum Psychopharmacol. 2010;25(4):303-309.

102. Tiwari AK, Zai CC, Likhodi O, et al. A common polymorphism in the cannabinoid receptor 1 (CNR1) gene is associated with antipsychoticinduced weight gain in Schizophrenia. Neuropsychopharmacology. 2010;35(6):1315-1324.

103. Reynolds GP. Pharmacogenetic aspects of antipsychotic drug-induced weight gain - a critical review. Clin Psychopharmacol Neurosci. 2012;10(2):71-77.

104. Wang YC, Bai YM, Chen JY, Lin CC, Lai IC, Liou YJ. Polymorphism of the adrenergic receptor alpha $2 \mathrm{a}-1291 \mathrm{C}>\mathrm{G}$ genetic variation and clozapine-induced weight gain. J Neural Transm (Vienna). 2005;112(11):1463-1468.

105. Czerwensky F, Leucht S, Steimer W. MC4R rs489693: a clinical risk factor for second generation antipsychotic-related weight gain? Int $J$ Neuropsychopharmacol. 2013;16(9):2103-2109.

106. Chowdhury NI, Tiwari AK, Souza RP, et al. Genetic association study between antipsychotic-induced weight gain and the melanocortin-4 receptor gene. Pharmacogenomics J. 2013;13(3):272-279.

107. Zai GC, Zai CC, Chowdhury NI, et al. The role of brain-derived neurotrophic factor (BDNF) gene variants in antipsychotic response and antipsychotic-induced weight gain. Prog Neuropsychopharmacol Biol Psychiatry. 2012;39(1):96-101.

108. Mulder H, Franke B, van der-Beek van der AA, et al. The association between HTR2C gene polymorphisms and the metabolic syndrome in patients with schizophrenia.JClin Psychopharmacol. 2007;27(4):338-343.

109. Mulder H, Cohen D, Scheffer H, et al. HTR2C gene polymorphisms and the metabolic syndrome in patients with schizophrenia: a replication study. J Clin Psychopharmacol. 2009;29(1):16-20.
110. Bai YM, Chen TT, Liou YJ, Hong CJ, Tsai SJ. Association between HTR2C polymorphisms and metabolic syndrome in patients with schizophrenia treated with atypical antipsychotics. Schizophr Res. 2011;125(2-3):179-186.

111. Risselada AJ, Vehof J, Bruggeman R, et al. Association between HTR2C gene polymorphisms and the metabolic syndrome in patients using antipsychotics: a replication study. Pharmacogenomics $J$. 2012;12(1):62-67.

112. Liou YJ, Bai YM, Lin E, et al. Gene-gene interactions of the INSIG1 and INSIG2 in metabolic syndrome in schizophrenic patients treated with atypical antipsychotics. Pharmacogenomics J. 2012;12(1):54-61.

113. Liou YJ, Tsai SJ, Wang YC, Bai YM, Hong CJ. Genetic variants of microsomal triglyceride transfer protein (MTTP) are associated with metabolic syndrome in schizophrenic patients treated with atypical antipsychotics. J Clin Psychopharmacol. 2013;33(3):313-318.

114. van Winkel R, Rutten BP, Peerbooms O, Peuskens J, van Os J, De Hert M. MTHFR and risk of metabolic syndrome in patients with schizophrenia. Schizophr Res. 2010;121(1-3):193-198.

115. Adkins DE, Åberg K, McClay JL, et al. Genomewide pharmacogenomic study of metabolic side effects to antipsychotic drugs. Mol Psychiatry. 2011;16(3):321-332.

116. Smith RC, Segman RH, Golcer-Dubner T, Pavlov V, Lerer B. Allelic variation in ApoC3, ApoA5 and LPL genes and first and second generation antipsychotic effects on serum lipids in patients with schizophrenia. Pharmacogenomics J. 2008;8(3):228-236.

117. Lally J, MacCabe JH. Personalised approaches to pharmacotherapy for schizophrenia. Adv Psychiatr Treat. 2016;22(2):78-86.

118. Potkin SG, Basile VS, Jin Y, et al. D1 receptor alleles predict PET metabolic correlates of clinical response to clozapine. Mol Psychiatry. 2003;8(1):109-113.

119. Hwang R, Shinkai T, De Luca V, et al. Association study of four dopamine D1 receptor gene polymorphisms and clozapine treatment response. J Psychopharmacol. 2007;21(7):718-727.

120. Hwang R, Shinkai T, De Luca V, et al. Association study of 12 polymorphisms spanning the dopamine $\mathrm{D}(2)$ receptor gene and clozapine treatment response in two treatment refractory/intolerant populations. Psychopharmacology (Berl). 2005;181(1):179-187.

121. Szekeres G, Keri S, Juhasz A, et al. Role of dopamine D3 receptor (DRD3) and dopamine transporter (DAT) polymorphism in cognitive dysfunctions and therapeutic response to atypical antipsychotics in patients with schizophrenia. Am J Med Genet B Neuropsychiatr Genet. 2004;124B(1):1-5.

122. Hwang R, Shinkai T, Deluca V, et al. Dopamine D2 receptor gene variants and quantitative measures of positive and negative symptom response following clozapine treatment. Eur Neuropsychopharmacol. 2006;16(4):248-259.

123. Malhotra AK, Goldman D, Buchanan RW, et al. The dopamine D3 receptor (DRD3) Ser9Gly polymorphism and schizophrenia: a haplotype relative risk study and association with clozapine response. Mol Psychiatry. 1998;3(1):72-75.

124. Masellis M, Basile V, Meltzer HY, et al. Serotonin subtype 2 receptor genes and clinical response to clozapine in schizophrenia patients. Neuropsychopharmacology. 1998;19(2):123-132.

125. Arranz MJ, Collier DA, Munro J, et al. Analysis of a structural polymorphism in the 5-HT2A receptor and clinical response to clozapine. Neurosci Lett. 1996;217(2-3):177-178.

126. Sodhi MS, Arranz MJ, Curtis D, et al. Association between clozapine response and allelic variation in the 5-HT2C receptor gene. Neuroreport. 1995;7(1):169-172.

127. Malhotra AK, Goldman D, Ozaki N, Breier A, Buchanan R, Pickar D. Lack of association between polymorphisms in the 5-HT2A receptor gene and the antipsychotic response to clozapine. Am J Psychiatry. 1996;153(8):1092-1094.

128. Hamdani N, Bonniere M, Ades J, Hamon M, Boni C, Gorwood P. Negative symptoms of schizophrenia could explain discrepant data on the association between the 5-HT2A receptor gene and response to antipsychotics. Neurosci Lett. 2005;377(1):69-74. 
129. Nothen MM, Rietschel M, Erdmann J, et al. Genetic variation of the 5-HT2A receptor and response to clozapine. Lancet. 1995;346(8979): 908-909.

130. Malhotra AK, Goldman D, Ozaki N, et al. Clozapine response and the 5HT2C Cys23Ser polymorphism. Neuroreport. 1996;7(13):2100-2102.

131. Masellis M, Basile VS, Meltzer HY, et al. Lack of association between the T-->C 267 serotonin 5-HT6 receptor gene (HTR6) polymorphism and prediction of response to clozapine in schizophrenia. Schizophr Res. 2001;47(1):49-58.

132. Opgen-Rhein C, Brandl EJ, Muller DJ, et al. Association of HTR2C, but not LEP or INSIG2, genes with antipsychotic-induced weight gain in a German sample. Pharmacogenomics. 2010;11(6):773-780.

133. Czerwensky F, Leucht S, Steimer W. Association of the common MC4R rs17782313 polymorphism with antipsychotic-related weight gain. J Clin Psychopharmacol. 2013;33(1):74-79.

134. Lubrano-Berthelier C, Dubern B, Lacorte JM, et al. Melanocortin 4 receptor mutations in a large cohort of severely obese adults: prevalence, functional classification, genotype-phenotype relationship, and lack of association with binge eating. J Clin Endocrinol Metab. 2006;91(5):1811-1818.

135. Hong CJ, Liou YJ, Bai YM, Chen TT, Wang YC, Tsai SJ. Dopamine receptor D2 gene is associated with weight gain in schizophrenic patients under long-term atypical antipsychotic treatment. Pharmacogenet Genomics. 2010;20(6):359-366.

136. Huang HH, Wang YC, Wu CL, et al. TNF-alpha -308 G>A polymorphism and weight gain in patients with schizophrenia under longterm clozapine, risperidone or olanzapine treatment. Neurosci Lett. 2011;504(3):277-280.

137. Reichenberg A, Mill J, MacCabe JH. Epigenetics, genomic mutations and cognitive function. Cogn Neuropsychiatry. 2009;14(4-5): 377-390.

138. Boks MP, de Jong NM, Kas MJ, et al. Current status and future prospects for epigenetic psychopharmacology. Epigenetics. 2012;7(1):20-28.

139. Petronis A. The origin of schizophrenia: genetic thesis, epigenetic antithesis, and resolving synthesis. Biol Psychiatry. 2004;55(10):965-970.

140. Mill J, Tang T, Kaminsky Z, et al. Epigenomic profiling reveals DNAmethylation changes associated with major psychosis. Am J Hum Genet. 2008;82(3):696-711.

141. Guidotti A, Auta J, Chen Y, et al. Epigenetic GABAergic targets in schizophrenia and bipolar disorder. Neuropharmacology. 2011;60(7-8): 1007-1016.

142. Matrisciano F, Dong E, Gavin DP, Nicoletti F, Guidotti A. Activation of group II metabotropic glutamate receptors promotes DNA demethylation in the mouse brain. Mol Pharmacol. 2011;80(1):174-182.

143. Huang HS, Matevossian A, Whittle C, et al. Prefrontal dysfunction in schizophrenia involves mixed-lineage leukemia 1-regulated histone methylation at GABAergic gene promoters. J Neurosci. 2007; 27(42):11254-11262.

144. Dong E, Nelson M, Grayson DR, Costa E, Guidotti A. Clozapine and sulpiride but not haloperidol or olanzapine activate brain DNA demethylation. Proc Natl Acad Sci USA. 2008;105(36):13614-13619.

145. Howes OD, Kapur S. A neurobiological hypothesis for the classification of schizophrenia: type A (hyperdopaminergic) and type B (normodopaminergic). Br J Psychiatry. 2014;205(1):1-3.

146. Lally J, Ajnakina O, Di Forti M, et al. Two Distinct Patterns of Treatment Resistance: Clinical Predictors of Treatment Resistance in First-Episode Schizophrenia Spectrum Psychoses. Psychol Med. 2016; 1-10. DOI: 10.1017/s0033291716002014

147. Schennach R, Riedel M, Musil R, Moller HJ. Treatment response in first-episode schizophrenia. Clin Psychopharmacol Neurosci. 2012; 10(2):78-87.

148. Hassan AN, De Luca V. The effect of lifetime adversities on resistance to antipsychotic treatment in schizophrenia patients. Schizophr Res. 2015;161(2-3):496-500.

149. Frank J, Lang M, Witt SH, et al. Identification of increased genetic risk scores for schizophrenia in treatment-resistant patients. Mol Psychiatry. 2015;20(2):150-151.
150. Wimberley T, Støvring H, Sørensen HJ, Horsdal HT, MacCabe JH, Gasse C. Predictors of treatment resistance in patients with schizophrenia: a population-based cohort study. Lancet Psychiatry. 2016;3(4):358-366.

151. Vanelle JM. [Treatment refractory schizophrenia]. Encephale. 1995; 21(3):13-21. French.

152. Meltzer HY, Rabinowitz J, Lee MA, et al. Age at onset and gender of schizophrenic patients in relation to neuroleptic resistance. Am J Psychiatry. 1997;154(4):475-482.

153. Martin AK, Mowry B. Increased rare duplication burden genomewide in patients with treatment-resistant schizophrenia. Psychol Med. 2016;46(3):469-476.

154. Lieberman JA, Safferman AZ, Pollack S, et al. Clinical effects of clozapine in chronic schizophrenia: response to treatment and predictors of outcome. Am J Psychiatry. 1994;151(12):1744-1752.

155. Semiz UB, Cetin M, Basoglu C, et al. Clinical predictors of therapeutic response to clozapine in a sample of Turkish patients with treatmentresistant schizophrenia. Prog Neuropsychopharmacol Biol Psychiatry. 2007;31(6):1330-1336.

156. Pickar D, Owen RR Jr, Litman RE, Hsiao JK, Su TP. Predictors of clozapine response in schizophrenia. J Clin Psychiatry. 1994;55 append B:129-132.

157. Rosenheck R, Lawson W, Crayton J, et al. Predictors of differential response to clozapine and haloperidol. Veterans Affairs Cooperative Study Group on Clozapine in Refractory Schizophrenia. Biol Psychiatry. 1998;44(6):475-482.

158. Umbricht DS, Wirshing WC, Wirshing DA, et al. Clinical predictors of response to clozapine treatment in ambulatory patients with schizophrenia. J Clin Psychiatry. 2002;63(5):420-424.

159. Ucok A, Cikrikcili U, Karabulut S, et al. Delayed initiation of clozapine may be related to poor response in treatment-resistant schizophrenia. Int Clin Psychopharmacol. 2015;30(5):290-295.

160. Nielsen J, Nielsen RE, Correll CU. Predictors of clozapine response in patients with treatment-refractory schizophrenia: results from a Danish Register Study. J Clin Psychopharmacol. 2012;32(5): 678-683.

161. Ikeda M, Yoshimura R, Hashimoto R, et al. Genetic overlap between antipsychotic response and susceptibility to schizophrenia. J Clin Psychopharmacol. 2015;35(1):85-88.

162. Hettige NC, Cole CB, Khalid S, De Luca V. Polygenic risk score prediction of antipsychotic dosage in schizophrenia. Schizophr Res. 2016;170(2-3):265-270.

163. Malhotra AK, Correll CU, Chowdhury NI, et al. Association between common variants near the melanocortin 4 receptor gene and severe antipsychotic drug-induced weight gain. Arch Gen Psychiatry. 2012;69(9):904-912.

164. Jameson JL, Longo DL. Precision medicine -- personalized, problematic, and promising. N Engl J Med. 2015;372(23):2229-2234.

165. Joyner MJ, Paneth N. Seven questions for personalized medicine. JAMA. 2015;314(10):999-1000.

166. Shabaruddin FH, Fleeman ND, Payne K. Economic evaluations of personalized medicine: existing challenges and current developments. Pharmacogenomics Pers Med. 2015;8:115-126.

167. Evers K. Personalized medicine in psychiatry: ethical challenges and opportunities. Dialogues Clin Neurosci. 2009;11(4):427-434.

168. Stanek EJ, Sanders CL, Taber KA, et al. Adoption of pharmacogenomic testing by US physicians: results of a nationwide survey. Clin Pharmacol Ther. 2012;91(3):450-458.

169. Malhotra AK, Zhang JP, Lencz T. Pharmacogenetics in psychiatry: translating research into clinical practice. Mol Psychiatry. 2012;17(8):760-769.

170. Hoop JG, Lapid MI, Paulson RM, Roberts LW. Clinical and ethical considerations in pharmacogenetic testing: views of physicians in 3 "early adopting" departments of psychiatry. J Clin Psychiatry. 2010;71(6):745-753.

171. Crews KR, Hicks JK, Pui CH, Relling MV, Evans WE. Pharmacogenomics and individualized medicine: translating science into practice. Clin Pharmacol Ther. 2012;92(4):467-475. 


\section{Publish your work in this journal}

Pharmacogenomics and Personalized Medicine is an international, peerreviewed, open access journal characterizing the influence of genotype on pharmacology leading to the development of personalized treatment programs and individualized drug selection for improved safety, efficacy and sustainability. This journal is indexed on the American Chemical
Society's Chemical Abstracts Service (CAS). The manuscript management system is completely online and includes a very quick and fair peer-review system, which is all easy to use. Visit http://www.dovepress. com/testimonials.php to read real quotes from published authors.

Submit your manuscript here: https://www.dovepress.com/pharmacogenomics-and-personalized-medicine-journal 